
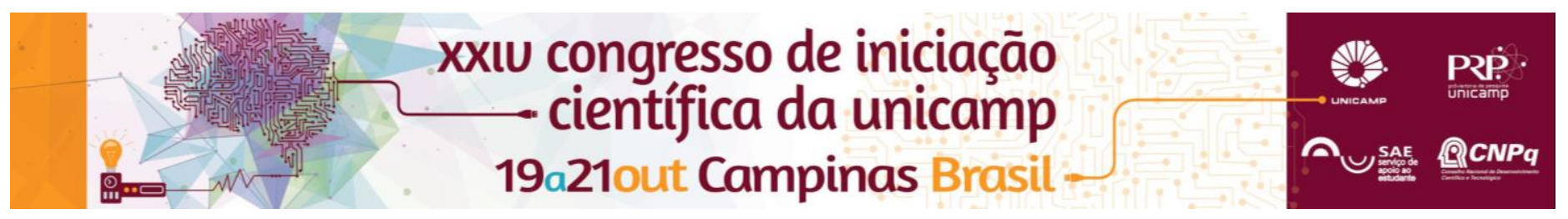

\title{
Avaliação de corantes alimentares por MALDI-Imaging
}

\author{
Mariana N. Tami*, Rodrigo R. Catharino, Diogo N. Oliveira.
}

\section{Resumo}

Os corantes constituem a principal classe de aditivos alimentares que são utilizados tanto pela indústria alimentícia quanto pela indústria farmacêutica. Eles são essenciais para a aceitabilidade do produto pelo consumidor e é preferível, quando comparado aos corantes naturais, a utilização de sintéticos graças a alta estabilidade físico-química, uniformidade da cor e baixo custo. Porém, muitos efeitos tóxicos estão associados ao seu consumo em grande quantidade e aos casos de adulteração. Por isso, novas técnicas rápidas, baratas e confiáveis são essenciais para a garantia da segurança alimentar.

\section{Palavras-chave:}

MALDI-Imaging, Corantes Alimentares, Indústria Farmacêutica.

\section{Introdução}

Com o desenvolvimento da indústria alimentícia no século XX a utilização de corantes alimentares foi essencial para aumentar a aceitabilidade dos produtos pelo consumidor e a variedade dos mesmos.

Dentre os corantes mais utilizados, tanto na indústria farmacêutica quanto na alimentícia, estão a eritrosina e o azul de indigotina. Ambos são corantes sintéticos apresentados na forma de pó vermelho e azul, respectivamente.

Todos os corantes, segundo a Agência Nacional de Vigilância Sanitária (ANVISA), devem ser detectados nas diferentes matrizes por métodos espectrofotométricos a fim de controlar a quantidade máxima permitida em cada produto.

No Brasil, a ANVISA impôs limites de concentração para os corantes dos diferentes gêneros alimentícios baseando-se em regulamentações internacionais. Contudo, de acordo com a legislação brasileira, a especificação da concentração real desse aditivo alimentar não é necessária ${ }^{1}$.

Esta situação aponta para a necessidade do desenvolvimento de métodos eficientes para a determinação dos corantes e que permitam maior controle no gênero alimentício, já que os níveis recomendados desses corantes ainda não são bem definidos pela literatura e novas evidências (in vitro e in vivo) têm sido apresentadas tanto em termos de carcinogenicidade e genotoxicidade para algumas destas substâncias ${ }^{2}$.

Desta forma, este estudo tem por objetivo o desenvolvimento de metodologia para a determinação e quantificação de corantes em matrizes alimentícias através da técnica de MALDI-MSI.

\section{Resultados e Discussão}

Visando a determinação e quantificação dos corantes alimentares em diferentes matrizes alimentícias foi desenvolvido um novo método por cromatografia em papel seguida de determinação e quantificação por MALDI-MSI.

Primeiramente tanto as soluções dos padrões de eritrosina e de azul de indigotina, quanto as soluções dos produtos alimentícios foram depositados no volume de $1 \mu \mathrm{L}$ em papel filtro. Estas soluções foram preparadas na proporção 1:1 (padrão do corante/matriz alimentícia:água). As matrizes alimentícias utilizadas foram confeitos coloridos (eritrosina) e suco em pó (azul de indigotina) adquiridos comercialmente. A fase móvel utilizada foi etanol:água (1:1).

Em seguida a matriz iônica (Ácido a-ciano-4hidroxicinâmico) diluída em acetonitrila e metanol (1:1) foi adicionada sobre o papel filtro.

Finalmente, para a determinação e quantificação dos corantes alimentares nas matrizes analisadas, as placas foram analisadas por MALDI-MSI.

A técnica desenvolvida foi bastante eficaz, como demonstrado nas figuras 1 (a) e (b), gráficos de quantificação dos corantes eritrosina e azul de indigotina, respectivamente.

Figura 1. (a) Quantificação do corante eritrosina e (b) quantificação do corante azul de indigotina.

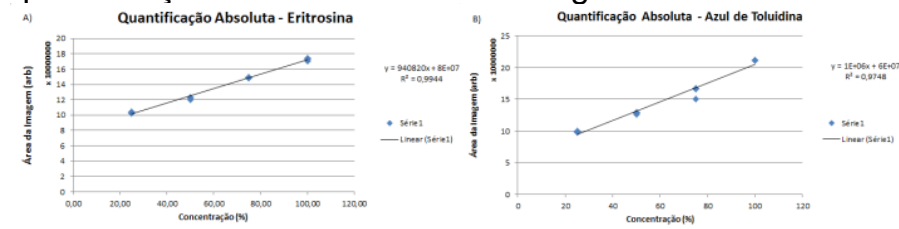

\section{Conclusões}

De acordo com os espectros de quantificação obtidos, pode-se concluir que o método que alia cromatografia em papel e determinação de quantificação por MALDI-MSI desenvolvida é totalmente eficaz para a quantificação de corantes alimentares em matrizes alimentícias.

\section{Agradecimentos}

Agradeço ao CNPq, a Universidade Estadual de Campinas e o Laboratório Innovare de Biomarcadores pela oportunidade de desenvolvimento deste projeto.

${ }^{1}$ Polonio, M., Peres, F., Consumo de aditivos alimentares e efeitos à saúde: desafios para a saúde pública brasileira. Cadernos de Saúde Pública, vol. 25(8), 2009.

${ }^{2}$ Yoshioka, N, Ishihashi, K., Determination of 40 synthetic food colors in drinks and candies by high-performance liquid chromatography using a short column with photodiode array detection. Talanta, 74, pp. 1408-1413, 2008 